\title{
Design and Simulation of a Waste Heat Recovery System for a Cement Manufacturing Process
}

\author{
Tharun Sivakumar \\ Dept. of Electronics \& Communication Engineering, \\ $R V$ College of Engineering \\ Bengaluru, India
}

\author{
Ravishankar Holla \\ Dept. of Electronics \& Communication Engineering, \\ $R V$ College of Engineering \\ Bengaluru, India
}

\begin{abstract}
As the ever-changing world continues to desperately look for alternative energy sources in the midst of an energy crisis, new technologies to recover power are revealing themselves and being implemented all across the globe. Most power plants are looking for more sustainable sources of energy over the long term. One such technology being adopted now by a lot of enterprises are Energy Recovery Systems. These systems work to retain and reuse energy that would otherwise be lost to the atmosphere after a certain process. They are sustainable and require comparatively lower capital. The objectives of this project revolve around the modelling of a Waste Heat Recovery System (WHRS) for a heat intensive manufacturing process. The heat, which would otherwise be lost to the atmosphere, is trapped and converted by a heat recovery unit into reusable energy. The main principle on which such a system would operate is The Rankine Cycle, an idealized thermodynamic cycle. A successful implementation of such an energy recovery system would not just boost the energy efficiency but also reduce the operational costs. The modelling and simulation of the heat recovery system is done on an open-source chemical process flow software known as DWSIM. An analysis of this heat recovery model shows an increase of $19.66 \%$ in the energy efficiency of the manufacturing process. Heat recovery systems also have great benefits for the environment, as they reduce the emissions of greenhouse gases by such manufacturing plants and help reduce global warming.
\end{abstract}

Keywords: Energy recovery; Heat recovery; DWSIM; Cement manufacturing; Production efficiency; Industrial boiler

\section{Introduction}

Energy recovery refers to any operations or techniques that work to increase the efficiency of a process by retaining the internal energy that would otherwise be lost. The Waste Heat Recovery System (WHRS) is a kind of energy recovery system that transfers heat from process outputs to other sub-processes as a form of usable energy. The WHRS captures heat that is "lost" or "wasted" and reuses it to improve the overall efficiency within industrial manufacturing operations. According to a survey done in cement manufacturing plants in 2013 [1], cement manufacturing plants spend an enormous $40 \%$ of their capital on just energy resources and fossil fuels to power up their manufacturing process. Thus, the employment of a WHRS also seeks to lower the operational costs of such power plants. Waste heat recovery systems retain the heat energy from the exhaust gas with the help of a few stages [2] - Waste Heat Boiler, Regenerator, Recuperator, Condenser, and in some cases, an Economiser - and convert it into electrical energy. Meanwhile, the remnant heat 
can further be used for miscellaneous services (such as preheating, domestic hot water, etc.). This technology has found applications in the industries of Cement, Glass, Steel and such. Dr. Anjoo Pandey [3] discusses the significance of the cement industry in India to reveal that it is one of the key factors for the economic growth of the country, and a major contributor to the Gross Domestic Product (GDP) of the same since it provides direct and indirect employment to a large population of the country. Being the second largest manufacturer of cement in the world, with a share of $8 \%$ of total world output, India exports over 2.8 million tonnes of cement every year, making the industry one of the highest benefactors towards the economy of the country. The major challenge, however, faced by the cement industry in recent years is the insufficient and irregular supply of quality coal and other energy sources. Thus, this is an industry where more sustainable energy sources are the need of the hour.

A review of papers on the cement manufacturing process made it clear that the most energy intensive stages in a cement power plant are the burning of raw meal in the preheater and the kiln, where flue gases (a mixture of gases possessing high amounts of heat energy and residual matter from the combustion of fossil fuel) are emitted in the order of hundreds of degrees Celsius. A great increase in the production efficiency can be expected if the thermal energy from these gases can be trapped and reused in other sub-processes. Thus, Waste Heat Recovery Units shall be modelled for heat recovery at both of these stages. This paper focuses on modelling a cement manufacturing process and a heat recovery system for the same, further calculating the energy efficiency of the manufacturing process with and without the heat recovery system.

\section{Literature Review}

Hussam Jouhara et al [2] define the term "Waste Heat" in detail to understand what it constitutes in the industrial sense. The authors talk about reusing 'lost' heat as a substitute for energy resources and increasing the energy efficiency. The various modern technologies to implement the WHRS have been discussed, including different forms of recuperators, regenerators, the Organic Rankine Cycle (ORC) and the Kalina cycle. The different stages of the WHRS, namely Boiler, Regenerator, Recuperator, Economiser along with different types of heat exchangers have been discussed in great detail. The various fluids/coolants that could be used within the heat recovery systems were also discussed, with water seeming like the best prospect due to its high specific heat capacity. Recovery methods in the steel, iron, food, and ceramic industries are reviewed.

Hussam Jouhara et al [4] explore the use of thermoacoustic engines and heat pyrolysis to carry out the energy conversions within the WHRS. Thermoacoustic engines, as the name suggests, make use of high amplitude sound waves for the purposes of transferring thermal energy. The environmental implications and benefits, apart from the energy savings within the process flow that are obtained by using a Waste Heat Recovery System are discussed. The employment of heat recovery systems also helps reduce the emissions of greenhouse gases.

C.-T. Hsu et al [5] have carried out simulations and experiments to determine the feasibility of thermoelectric modules (mimicking a heat recovery system) for different applications. The application of thermoelectric generators to extract and reuse waste heat in automobiles is discussed. It is observed that almost $75 \%$ of the energy generated from the combustion of fuel in an automobile goes to waste as dissipated heat energy. The combination of a Bi2Te3-based thermoelectric generator and thermal resistors are the components of a vehicular heat recovery system in a simulation. The increased energy efficiency was calculated to be $2-3 \%$. 
J. Wang et al [6] discuss and assess the feasibility of a design idea that uses an absorption heat pump to salvage waste heat from the exhaust of a steam turbine for heating supply. Heat pump provides heat from a thermal source directly to a heat sink. They are designed to be able to extract heat from a region and release it into a comparatively warmer region. For specific units, the corresponding heat recovery systems were designed, and the energy economy of the system was assessed. It was concluded that a reasonable selection of the design power heat pump is crucial to improve the economy of the waste heat recovery system.

S.K. Gupta et al [7] acknowledge that on an average, cement plants lose about 35\% of the heat they are providing. This heat is majorly lost in the preheater and the waste gases from the cooler. The authors discuss how largely WHRS contribute toward energy optimization and savings, and seek to reduce $\mathrm{CO} 2$ emissions, thus improving the quality of the environment. It is acknowledged that a significant portion of the operating costs in a cement power plant goes towards paying for the energy resources. Thus, with the implementation of a WHRS, the operating costs can also be reduced. The working of the Organic Rankine Cycle is explained, along with waste heat potentials of multi-preheater plants. It is acknowledged that heat recovery systems are a need of the hour and in order to protect the interests of our environment by reducing the carbon and greenhouse gases emissions. On average, installing a WHRS has shown to increase energy savings by $25 \%$.

H. Bruce [8] has shown comprehensive demographics of all the various countries who have implemented industrial heat recovery. It is clear that China has a marginal lead over all the other countries over the number of WHRSs implemented in their power plants (as of 2014). The reason behind China's big numbers are the regulatory measures set by the government and low initial capitals for the waste heat recovery systems. It is clear that WHRS are implemented to reduce operational costs and improve the EBITDA margins of the cement power plants by $10-15 \%$. The Steam Rankine Cycle, Organic Rankine Cycle and the Kalina Cycle were all discussed in-depth. It is discussed that the heat recovered by a WHRS in a cement plant would depend on a few factors, such as the amount of moisture in the raw meal, number and efficiency of the preheater and kiln stages, amount of excess air in the kiln, and amount of air infiltration. The WHRS, though it has a high initial capital, is economical in the long run since the running costs are low and it reduces the daily operating costs. The author then discusses the Waste Heat Recovery System from the perspective of each country. India, the country with the second most number of heat recovery systems implemented in power plants, is encouraging all such power plants to employ waste heat recovery systems by giving them tax and depreciation benefits. Due to the high power demand in India, WHRSs are beneficial.

A. Beyene et al [9] discuss the modelling of a waste heat recovery system of different energy ranges by following the Organic Rankine Cycle. The software used for this modelling and simulation is the CAMEL-Pro, a thermodynamics configured simulation environment. The interesting feature of this software is that it allows the use of organic coolants such as R245fa, R600, and more. An upside to modelling the WHRS for marine operations is that there is unlimited supply of cool water that can be used to heat the water or coolant inside the WHRS. As expected, the addition of a WHRS provided better efficiency, power output and exhaust gas temperature.

J.I. Chowdhury et al [10] recognize the evaporator and superheater of the WHRS to be the most important component of the cement manufacturing process as it defines the efficiency of the whole process. To reduce the computational time at the evaporator in a Finite Volume model, a fuzzy based evaporator is considered. A fuzzy logic is a logic that is not binary, so it can take the values $1-100 \%$ and anything in between. The fuzzy evaporator model here predicts the evaporator with a precision of over $90 \%$ whilst reducing 
the simulation time. The fuzzy based logic does not increase the energy efficiency or power output of the whole process, instead it predicts the output values more accurately than before, which are again, very important values.

Kwanchanok Tangsriwong et al [11] discuss and recognize the significance of chemical process flow and modelling software in the chemical industry. These software often handle a large amount of dynamic data and analysis during simulations and hence need to be programmed well. The authors have carried out a performance comparison between two such software - the commercial software 'Aspen Plus' and the open-source software 'DWSIM'. Both the software were used to model complex gas compression processes under steady state conditions, negligible pressure losses and adiabatic conditions. It was found through an analysis of the results obtained from simulations of the same process that the difference in the results between Aspen Plus and DWSIM was less than $5 \%$. It was concluded that DWSIM could carry out chemical process simulations as well as other commercial software.

C. R. Gustav Haby [12] through this research simulates a waste heat recovery system for automotive vehicles based on the Rankine Cycle on SIMULINK. The author mentions that heat energy recovery on vehicles could give great yield. Using heat recovery equations, the boiler, cooler, condenser, and recuperator are modelled on MATLAB \& SIMULINK. The author has used energy exchange equations on SIMULINK to depict the heat exchanges in these stages of the WHRS. After the simulations are run, it is concluded that the heat recovery system will only prove useful over highways and rural areas, since the vehicle would be at a constant speed (if not accelerating) and hence a continuous output from the exhaust would serve as an input to the WHRS. In the city conditions, that will not be the case and hence the heat recovery system will not be useful.

\section{Stages of Waste Heat Recovery System}

The Waste Heat Recovery system works on the principle of The Organic Rankine Cycle, a basic thermodynamic cycle that describes processes where heat energy is extracted from an organic working fluid and converted into useful mechanical work or electrical energy [13]. The stages of heat recovery are as follows:

1) Heat Pump - A pressure-altering device that is used to transport heat from the source of heat to a destination. Heat pumps are designed to move heat energy opposite to the direction of spontaneous thermal energy flow.

2) Waste heat Boiler (WHB) - uses the heat from the incoming gases/streams to heat up a fluid (usually water) to create steam. This steam can either be used on its own to turn a turbine, or in turn heat up another suitable coolant.

3) Recuperator - a type of heat exchanger in which heat is transferred to incoming gaseous material from waste hot gases coming from a furnace which are conducted along a series of flues.

4) Cooler or Regenerator - Where the incoming flue gas (after losing energy to WHB) is cooled down considerably by a coolant, before being safely expelled from the manufacturing. The hot gases are stored indefinitely till they lose their heat to a cooler fluid.

5) Expander/Turbine - Used to absorb heat from any incoming gases/fluids and turn it into mechanical energy and further into electrical energy.

6) Economiser (Optional) - Stand alone heat exchangers meant to further increase the energy efficiency of the Waste Heat Boiler by passing the waste heat in the exhaust flue gases across the outside of the metal tubes which contain feedwater within to facilitate the increase of their temperature before they enter the boiler. 
Thus, the Waste Heat Recovery Units modelled for the preheater and kiln shall have the above stages.

\section{Design on DWSIM}

The modelling of the cement manufacturing process and the Waste Heat Recovery System was done on the open-source chemical process flow simulator, DWSIM. The factory equipment parameters such as flow rate, temperature, pressure, volume of tanks were obtained by studying Piping \& Instrumentation Diagrams (P\&IDs) of the cement manufacturing process. These parameters facilitate the accurate modelling of the process flows. Since the aim is to calculate just the energy efficiency, only the energy intensive part of the cement production process is depicted.

As depicted in Figure 1, the cement manufacturing process is modelled by setting up a pump to pump in raw meal into the preheater, then the kiln.

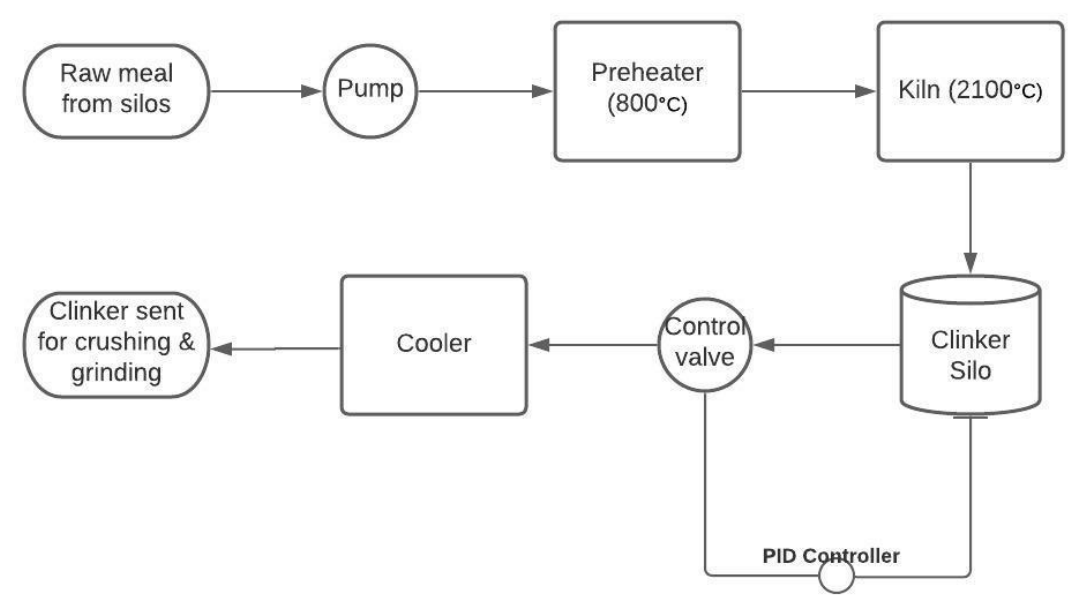

Figure 1. Block diagram of the cement manufacturing process modelled on DWSIM.

In these processes the raw meal is mixed and heated up to $2250^{\circ} \mathrm{C}$ (as indicated by piping $\&$ instrumentation diagrams). The clinker coming out of the kiln is stored in a tank, where the clinker is mixed and blended. A PID controller manipulating a control valve at the output of the tank releases the clinker into a cooler whenever the tank gets sufficiently full. The cooler extracts the heat from the clinker to cool it down sufficiently before it is sent for further processing.

Next, a Waste Heat Recovery System is modelled for the flue gases released from the Kiln. First, the flue gases were depicted using a heater that releases hot air. By referring to the P\&IDs, it was clear that the temperature of the flue gases ejected out of the kiln was $916^{\circ} \mathrm{C}$ and that of the flue gases ejected out of the kiln were $347^{\circ} \mathrm{C}$. The flow rate of the flue gases was approximately $75 \mathrm{~kg} / \mathrm{s}$ in both the kiln and preheater. The flow rate values have been scaled down by a factor of 10 to facilitate calculations (Figure 2). 


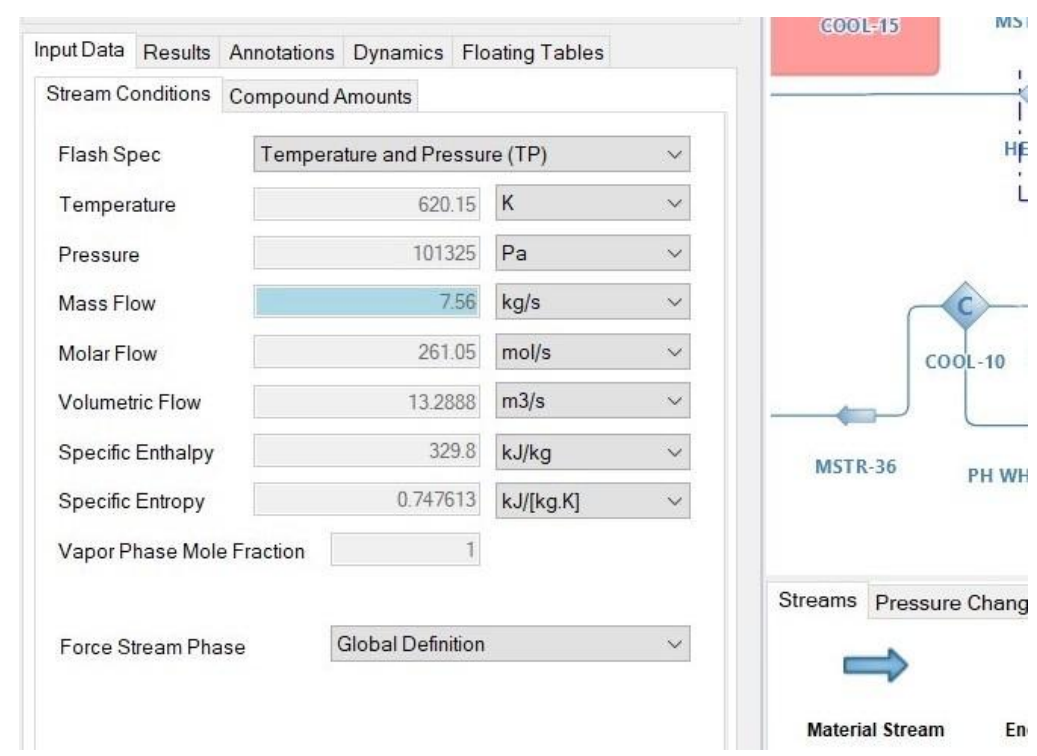

Figure 2. Parameters used in the modelling process were obtained from P\&IDs and scaled down.

The flue gases are made to go up the pipes into a WHRS, which consists of a Superheater \& Evaporator (Boiler), Cooler, Condenser and Recuperator. The materials involved in the flow within the WHRS are air, water and the R123 coolant (Freon). The incoming flue gases from the kiln are made to impart their heat energy to water in the Boiler, which subsequently heats up the R123 coolant to vaporize it and make it turn a turbine, thus producing electricity (Figure 3). The R123 coolant is preferred over water in this case due to its low boiling point of $27^{\circ} \mathrm{C}$ and its high specific gaseous heat energy. The R123 coolant, after losing its energy at the turbine, is further cooled down by passing through the recuperator and condenser before being pumped into the heat recovery boiler again, thus completing the cycle.

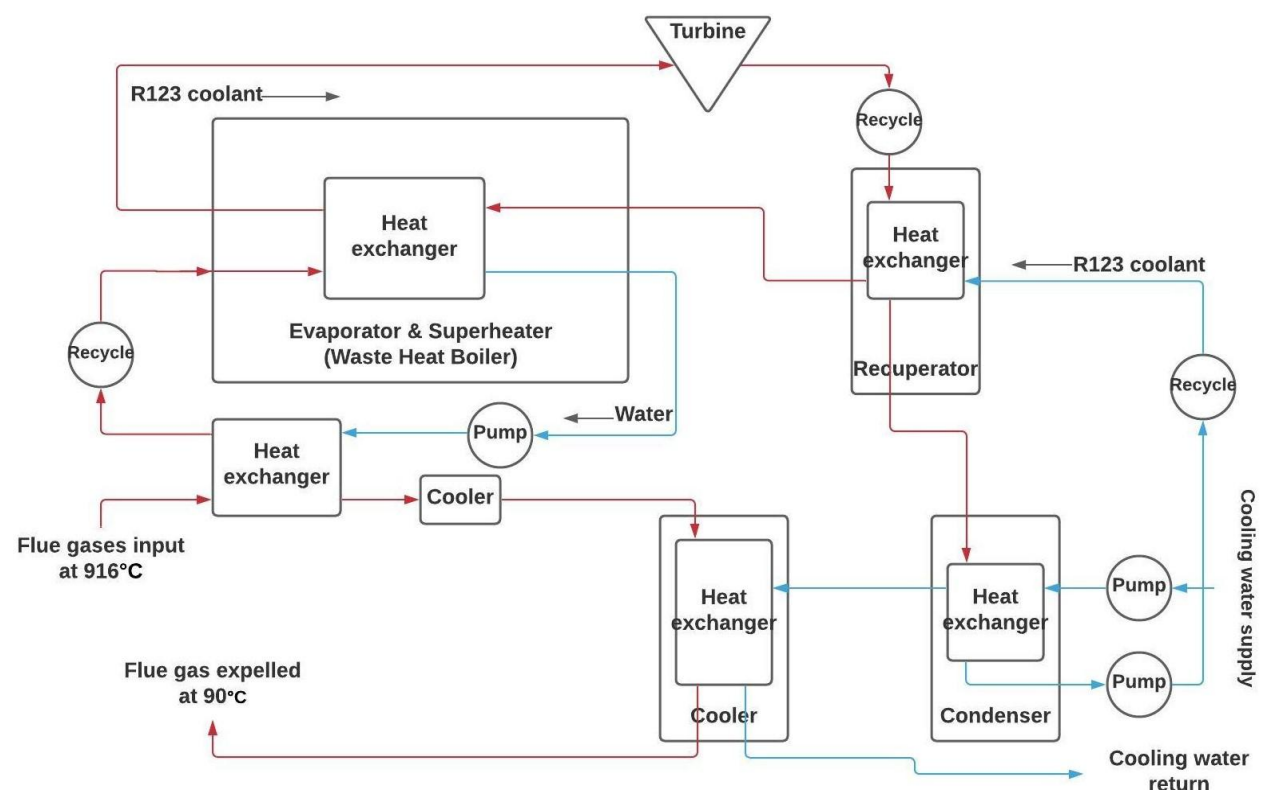

Figure 3. Block diagram of the WHRS modelled for the Kiln on DWSIM.

The flue gas, meanwhile, loses most of its energy in boiling the contents of the boiler. It is further cooled down, releasing a significant amount of energy to be reused. Finally it goes 
down to the Cooler, where it is cooled down to a temperature of $90^{\circ} \mathrm{C}$ with the help of a cooling water supply, before being released to the atmosphere.

The role of the cooling water in the WHRS is to cool down the R123 coolant before pumping it back for reuse, and cooling down the flue gases before ejecting them out safely to the environment at $90^{\circ} \mathrm{C}$.

Similarly, a heat recovery unit is modelled for the pre-heater and hence, the whole WHRS for the cement manufacturing process is modelled and prepared for simulation.

\section{Results}

After the cement manufacturing process and the WHRS are successfully modelled on DWSIM, a simulation is performed to ensure the correct working of the entire system and obtain data of energy inflow and outflow. The energy inflow and outflow could also be used to precisely find out the production efficiencies of the process flow with and without the use of a WHRS.

The formula used to find efficiency in each step is

$$
\eta=\text { Energy obtained/Energy Supplied }
$$

Since the software of DWSIM does not take into account the inefficiencies of mechanical processes and equipment (which do exist practically), an assumption was made that the heaters in the power plant were only $75 \%$ efficient. This was an added parameter to the heater objects in the preheater and kiln in the modelling process on DWSIM, in an attempt to make the models more accurate to the practical case.

- Cement manufacturing process without heat recovery

Considering the first case, when the cement manufacturing process was modelled without the WHRS, the energy inflow and outflow values obtained on simulation are as follows (Table 1).

table I. Cement Manufacturing Energy Flow

\begin{tabular}{|c|c|c|c|c|}
\hline & \multicolumn{3}{|c|}{ Cement Manufacturing Energy Flow } & \multirow{2}{*}{ Cooler output } \\
\hline Object & Pump input & Preheater input & Kiln input & Connn \\
\hline Energy Flow (kw) & 2.05305 & 5449.94 & 8959.73 & 9339.45 \\
\hline
\end{tabular}

Therefore,

The Energy Supplied $=(2.05305+5449.94+8959.73) \mathrm{kW}=14411.72305 \mathrm{~kW}$

The Energy Obtained $=9339.45 \mathrm{~kW}$

Thus, the energy efficiency comes out to be

$\eta=$ Energy obtained / Energy Supplied

$=9339.45 / 14411.72305$

$=0.6480 \approx 64.8 \%$

$\circ \quad$ Cement manufacturing process with heat recovery

Considering the second case, where the WHRS was modelled to recover heat from both the preheater and the kiln, the energy inflow and outflow values obtained after simulation are as follows (Table 2).

TABLE II. WHRS ENERgY FLow 


\begin{tabular}{|c|c|c|c|c|}
\hline Object & Pump input & Preheater input & Kiln input & Cooler output \\
\hline Energy Flow $(\mathrm{kw})$ & 2.05305 & 5449.94 & 8959.73 & 9339.45 \\
\hline
\end{tabular}

\begin{tabular}{|c|c|c|c|c|c|}
\hline & \multicolumn{3}{|c|}{ Preheater WHRS Energy Flow } & \multirow[b]{2}{*}{$\begin{array}{c}\text { WHRS } \\
\text { output1 }\end{array}$} & \multirow[b]{2}{*}{ WHRS output 2} \\
\hline Object & $\begin{array}{l}\text { WHRS } \\
\text { input1 }\end{array}$ & $\begin{array}{l}\text { WHRS } \\
\text { input2 }\end{array}$ & $\begin{array}{l}\text { WHRS } \\
\text { input3 }\end{array}$ & & \\
\hline $\begin{array}{l}\text { Energy Flow } \\
(k w)\end{array}$ & 0.01384 & 2.4080 & 2.65 & 440.416 & 487.21 \\
\hline & \multicolumn{3}{|c|}{ Kiln WHRS Flow } & & \\
\hline Object & $\begin{array}{l}\text { WHRS } \\
\text { input1 }\end{array}$ & $\begin{array}{l}\text { WHRS } \\
\text { input2 }\end{array}$ & $\begin{array}{l}\text { WHRS } \\
\text { input3 }\end{array}$ & $\begin{array}{c}\text { WHRS } \\
\text { output1 } \\
\end{array}$ & WHRS output 2 \\
\hline $\begin{array}{l}\text { Energy Flow } \\
(k w)\end{array}$ & 0.01977 & 3.0105 & 18.507 & 1078.46 & 849.405 \\
\hline
\end{tabular}

Therefore,

The Energy Supplied $=(2.05305+5449.94+8959.73+2.65+2.40804+0.0138483+$ $18.5707+3.01052+0.0197733) \mathrm{kW}=14438.3959316 \mathrm{~kW}$

The Energy Obtained $=(9339.45+440.416+487.21+1078.46+849.405) \mathrm{kW}=$ $12194.941 \mathrm{~kW}$

Thus, the energy efficiency for this case is

$$
\begin{aligned}
\eta(\text { WHRS }) & =\text { Energy obtained / Energy Supplied } \\
& =12194.941 / 14438.396 \\
& =0.8446 \approx 84.46 \%
\end{aligned}
$$

Thus, the employment of a WHRS increases the energy efficiency of the modelled cement manufacturing process from $64.80 \%$ to $84.46 \%$. That is an increase of $19.66 \%$ in energy efficiency.

Moreover, the Energy Recovered by the use of a WHRS = Outputs from WHRS - Inputs to WHRS

$=(440.416+487.21+1078.46+849.405)-(2.65+2.40804+0.0138483+18.5707+$ $3.01052+0.0197733) \mathrm{kW}=2828.8181184 \mathrm{~kW}$

The recovered energy could thus be reused within the process, perhaps for preheating, or a steady and reliable source of electrical energy, or domestic hot water supply.

\section{Conclusion}

The aim of this project was to model and simulate a cement production process and a Waste Heat Recovery System within the process to retain heat that would otherwise be lost to the atmosphere and turn it into a form of reusable energy. Then finally, compare the efficiency of the production process with and without the heat recovery system, to determine how much of an effect it has. This was achieved by: -

- $\quad$ Modelling the cement process flow on DWSIM after referring to P\&IDs.

- Modelling a WHRS for the process flow after gaining an in-depth understanding of the different stages and working of heat recovery systems.

- $\quad$ Finding energy inflow \& outflow data in both cases to validate the WHRS. 
The modelling of the WHRS was done on DWSIM enough to represent just the energy intensive processes. The piping $\&$ instrumentation diagrams were referred to in order to precisely replicate the process flow and the physical parameters of the manufacturing process and the power plant. The heat recovery system was aptly designed after identifying the processes where heat was lost - the preheater and the kiln. The heat recovery process was achieved through four stages - the waste heat recovery boiler, Cooler, Condenser and the Recuperator.

The Waste Heat Recovery System contributed to a tremendous increase in the energy efficiency of the cement manufacturing process. Simulations run on the process flow simulation software DWSIM showed a whopping $19.66 \%$ increase in energy efficiency of the manufacturing process after the WHRS was added. The WHRS, though demands a high initial capital, significantly lowers the operating costs of the manufacturing process.

The addition of a heat recovery system also has great environmental benefits. Considering the example of the model that was made on DWSIM, a flow of hot flue gases $\left(916^{\circ} \mathrm{C}\right)$ at the rate of $75.6 \mathrm{~kg} / \mathrm{s}$ is switched with a flow of flue gases of $90^{\circ} \mathrm{C}$ at the same rate. This indicates that millions of tonnes of greenhouse gases can be prevented from being released every day. This could help reduce the carbon footprint of such chemical power plants by reducing pollution drastically and reducing global warming.

\section{Acknowledgments}

The authors want to show gratitude towards the Department of Electronics and Communication of R.V. College of Engineering, Bengaluru for providing their unwavering support and resources throughout the course of this project.

Tharun Sivakumar expresses his gratitude towards his guide, Prof. Ravishankar Holla, Assistant Professor, Dept. of Electronics and Communication Engineering, RVCE and his mentor, Mr. Vivek R., Project Lead Engineer, Industrial Automation, ABB - Process Industries for their relentless support, guidance and encouragement.

Lastly, Tharun Sivakumar would like to thank all the friends and family members who provided all the backup support throughout the research work.

\section{REFERENCES}

[1] O. Ohunakin, O. Leramo, O. Abidakun, M. Odunfa, and O. Bafuwa, "Energy and cost analysis of cement production using the wet and dry processes in Nigeria," Energy and Power Engineering, vol. 05, pp. 537-550, Jan. 2013.

[2] Hussam Jouhara, Navid Khordehgah, Sulaiman Almahmoud, Bertrand Delpech, Amisha Chauhan, Savvas A. Tassou, "Waste heat recovery technologies and applications", Thermal Science and Engineering Progress, Volume 6, 2018.

[3] Anjoo Pandey, "Importance of Cement Industry in India," International Journal of Marketing and Technology Vol. 7 Issue 8, August 2017.

[4] H. Jouhara and A. G. Olabi, "Editorial: Industrial waste heat recovery," Energy, vol. 160, pp. 1-2, 2018.

[5] C.-T. Hsu, D.-J. Yao, K.-J. Ye, and B. Yu, "Renewable energy of waste heat recovery system for automobiles," Journal of Renewable and Sustainable Energy, vol. 2, Jan. 2010.

[6] J. Wang, W. Liu, G. Liu, W. Sun, G. Li, and B. Qiu, "Theoretical design and analysis of the waste heat recovery system of turbine exhaust steam using an absorption heat pump for heating supply," Energies, vol. 13, no. 23, 2020.

[7] S. K. G. /. S. K. Kaul, "Waste heat recovery power plants in cement," Holtec Consulting Private Ltd., 2015. 
[8] H. Bruce, "Waste heat recovery for the cement sector: Market and supplier analysis," Waste Heat Recovery for the Cement Sector, 2014.

[9] A. Beyene, S. Enrico, L. Tocci, and C. Toro, "Modelling and simulation of waste heat recovery systems for marine applications," Jul. 2015.

[10] J. I. Chowdhury, P. Soulatiantork, and B. K. Nguyen, "Simulation of waste heat recovery system with fuzzy based evaporator model," in 2017 11th Asian Control Conference (ASCC), 2017.

[11] Kwanchanok Tangsriwong, Puttida Lapchit, Tanatip Kittijungjit, Thepparat Klamrassamee,Yanin Sukjai, Yossapong Laoonual, "Modeling of chemical processes using commercial and open-source software: A comparison between Aspen Plus and DWSIM," IOP Conference Series: Earth and Environmental Science, vol. 463, Apr. 2020.

[12] C. R. Gustav Haby, Waste Heat Recovery Simulation Model based on the Rankine Cycle for Passenger Cars applications. Chalmers University of Technology, 2017.

[13] Tzu-Chen Hung, "Waste heat recovery of organic Rankine cycle using dry fluids", Energy Conversion and Management, Volume 42, Issue 5, 2001. 